\title{
IMAGEM DO ENFERMEIRO SOB A ÓTICA DO ACADÊMICO DE ENFERMAGEM
}

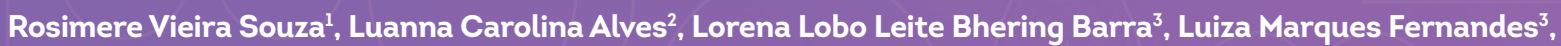
Patricia de Oliveira Salgado ${ }^{4}$, Selma Maria da Fonseca Viegas ${ }^{5}$

Objetivo: conhecer a imagem do enfermeiro frente ao acadêmico de enfermagem. Metodologia: estudo de caso qualitativo fundamentado na Sociologia Compreensiva do Cotidiano, realizado com 26 participantes do 9o período de uma instituição de ensino superior. Os dados foram coletados por meio da entrevista individual e analisados segundo Análise de Conteúdo Temática. Resultados: a imagem se postula em um profissional essencial na área da saúde, que organiza o setor, gerencia ações, lidera a equipe, presta assistência aos pacientes e é referência para outros profissionais. Conclusão: a (des)valorização do profissional foi um dos aspectos na construção dessa imagem e na percepção positiva/negativa do acadêmico frente ao futuro na profissão.

Descritores: Educação em Enfermagem, Imagem, Prática Profissional, Pessoal de Saúde, Enfermagem.

\section{IMAGE OF NURSE UNDER THE PERSPECTIVE OF THE NURSING ACADEMIC}

Objective: to know the image of the nurse in front of the nursing academic. Methodology: a qualitative case study based on the Comprehensive Sociology of Daily Life, carried out with 26 participants from the 9th period of an institution of higher education. The datas were collected through the individual interview and analyzed according to the Thematic Content Analysis. Results: The image postulates itself in a essencial professional in the health area, which organizes the sector, manages actions, leads the team, provides assistance to patients and is a reference for other professionals. Conclusion: The (de) valuation of the professional was one of the aspects in the construction of this image and in the positive / negative perception of the academic towards the future in the profession.

Descriptors: Education, Nursing, Image, Professional Practice, Health Personnel, Nursing

\section{IMAGEN DE ENFERMERAS DE LA PERSPECTIVA DE ENFERMERIAACADÉMICO}

Objetivo: conocer la imagen de la enfermera en el estudiante de enfermería. Metodología: estudio de caso cualitativo basado en la sociología comprensiva de la vida cotidiana, que se celebró con 26 participantes del noveno período de una institución de educación superior. Los datos fueron recolectados a través de entrevistas individuales y se analizaron mediante análisis de contenido temático. Resultados: La imagen se postula un profesional esencial en el campo de la salud, que organiza el sector, gestiona las acciones, dirige el equipo, ayuda a los pacientes y es un punto de referencia para otros profesionales. Conclusión: La (des) valoración profesional fue uno de los aspectos de la construcción de la imagen y la percepción positiva / negativa frente académico del futuro en la profesión.

Descriptores: Educación en Enfermería, Imagen, Práctica Profesional, Personal de Salud, Enfermería.

1Enfermeira.Pontificia Universidade Católica de Minas Gerais. E-mail: rosyvieira05_ita@hotmail.com

${ }^{2}$ Enfermeira. Especialista em Enfermagem do Trabalho.

${ }^{3}$ Enfermeira.Pontificia Universidade Católica de Minas Gerais.

${ }^{4}$ Enfermeira. Doutora em Enfermagem. Docente da Universidade Federal de Viçosa.

${ }^{5}$ Enfermeira. Doutora em Enfermagem. Docente da Universidade Federal de São João Del-Rei. 


\section{INTRODUÇÃO}

A enfermagem é uma ciência cujas essência e especificidade são o cuidado ao ser humano, individualmente, na familia ou em comunidade, de modo integral e equânime. O profissional enfermeiro desenvolve, de forma autônoma ou em equipe, atividades de promoção, proteção, reabilitação e recuperação da saúde, como também de prevenção de riscos e agravos. Assim, "utiliza da ciência, da arte, da estética e da ética para ações de cuidado destinadas a ajudar as pessoas a viverem mais saudáveis e, quando necessário, a superarem os efeitos da doença como um fenômeno social, existencial, cultural e transitório"(1:107).

$\mathrm{Na}$ enfermagem, a própria denominação enfermeiro não ajuda muito a definir a profissão, sobretudo para o público leigo, porque liga o nome a enfermo, doença ou enfermidade. Esse profissional tem uma atuação mais ampla, que inclui ações de promoção da saúde e prevenção de riscos e agravos.

Há descritas três imagens associadas à enfermeira: "a de mãe que cuida do filho, de doentes ou feridos; a da religiosa que cuidava de alguém como parte do cumprimento do dever cristão e a da enfermeira-servidora que surgiu na Europa protestante a partir do século XVI"(2:893). Essas imagens representam, por tradição e cultura, a feminilização da enfermagem. Nos últimos anos, pode-se afirmar que na enfermagem está se firmando uma tendência à masculinização da categoria, com o aumento da presença masculina na composição. Essa tendência é recente, data do início da década de 1990(3).

A imagem pode significar tanto o quadro que uma pessoa tem do objeto de sua vivência, quanto a opinião, contra ou a favor, que o público pode ter de uma instituição, organização ou personalidade ou ainda o conceito de que uma pessoa goza junto a outrem. Esse conceito está intimamente ligado à ideia de prestígio social e sua construção relaciona-se a concepções, sentimentos e atitudes ${ }^{(4)}$.

Em relação à profissão, a imagem de qualquer categoria profissional, na sociedade, pode ser associada a poder, reconhecimento e status. Por isso, o que a sociedade pensa do profissional é tão importante quanto aquilo que ele é; pois a projeção de uma imagem negativa dificulta o desenvolvimento da profissão e seu reconhecimento por parte da sociedade. A enfermagem tem utilizado pouco e mal os meios de comunicação para elucidar a comunidade científica e a população em geral sobre suas competências e seu papel na sociedade. Pesquisas no Brasil e no mundo retratam a "invisibilidade" do profissional em relação a seus clientes ${ }^{(5: 55)}$

Nos estágios curriculares, os graduandos podem observar de forma mais abrangente o atuar do enfermeiro, sua maneira de posicionar-se no trabalho, o que pode intervir em seu aprendizado e na visão que constroem do enfermeiro.

Nesse contexto, indagamos: qual a influência da formação acadêmica na construção da imagem do enfermeiro, perante os discentes de enfermagem de uma instituição de ensino superior de Minas Gerais?

O estudo teve como objetivo conhecer a imagem do enfermeiro frente ao acadêmico de enfermagem.

\section{METODOLOGIA}

Trata-se de estudo de caso qualitativo(6), fundamentado na Sociologia Compreensiva do Cotidiano(7)

O cenário foi o curso de graduação em enfermagem de uma universidade de Minas Gerais, com 114 graduandos de enfermagem que atendiam ao critério de inclusão: estar cursando 0 90 período da graduação nessa instituição. Foram selecionados por estarem no final do curso e terem tido mais contato com enfermeiros em campos de estágio. Assim, dos 114 acadêmicos, 26 foram entrevistados, considerando-se a saturação dos dados.

A coleta de dados foi realizada por meio de entrevista individual aberta, na qual os alunos responderam as seguintes questões: 1- Fale-me, mediante suas experiências acadêmicas e de vida, qual é a imagem que você tem do enfermeiro? 2- Essa imagem que você acabou de relatar modificou ou vem se modificando ao longo do Curso de Graduação em Enfermagem? Para a análise de dados utilizou-se da Análise de Conteúdo Temática ${ }^{(8)}$, originando duas categorias: Atuação do profissional enfermeiro; Contexto profissional: (des)valorização do enfermeiro.

O projeto de pesquisa foi aprovado sob o Parecer no 0220.0.213.000-11 do Comitê de Ética da Pontifícia Universidade Católica de Minas Gerais. Para garantir o anonimato dos participantes, foram utilizados pseudônimos. 


\section{RESULTADOS}

\section{Atuação do profissional enfermeiro}

A atuação profissional pode ser diversa e influenciar a formação de habilidades e de competências para atuação in loco: O enfermeiro do setor, geralmente, fica muito afastado do acadêmico, não gosta que a gente faça-lhe pergunta, ou então ele só dá assistência mesmo porque a instituição de uma maneira ou outra obriga (Amazonita). Ah, o enfermeiro ele é... o 'Norte', para o acadêmico?! Eu pude observar no estágio, sem ele nada funcionava... (Ametista). Eu vejo o enfermeiro como um profissional fundamental dentro da equipe multidisciplinar porque ele tá presente 24 horas dentro da instituição, ele tem essa relação mais próxima com o paciente (Esmeralda).

Os acadêmicos apontam a influência do perfil do enfermeiro sobre o processo de trabalho: Num hospital tinha andar que era todo organizado, o enfermeiro tinha uma bagagem de conhecimento,

ele buscava conhecimento mesmo. Tinha outro andar que era todo desorganizado, sabe, você via, era totalmente diferente um andar do outro numa mesma instituição. Então, assim, você vê o perfil do enfermeiro pela equipe que ele coordena (Diamante). 0 enfermeiro é um profissional que vai organizar o setor onde ele trabalha, primeiro com um espirito de liderança do pessoal e, depois, com a parte técnica (Ágata).

O modo como o enfermeiro

desempenha suas atividades referenciará toda sua equipe, ou seja, a habilidade, as competências, as atitudes e a liderança determinam seu perfil profissional. Dentre as diversas atribuições é necessário que o enfermeiro promova a interação entre os dicotômicos campos do cuidado e da administração: A gente vê que o enfermeiro tem que participar, tem que estar junto com sua equipe, trabalhar junto, para ter bons resultados. Se ele se isolar e achar que tá ali pra gerenciar a assistência, e não puser a mão na massa, eu acho que o trabalho fica incompleto (Ametrino). O enfermeiro é um grande articulador, uma pessoa que tem que ter uma visão de gestão muito grande, porque não é apenas o trabalho na assistência (Barita). Mas o que a gente consegue ver é que o enfermeiro, aquele que a gente aprende ser enfermeiro na faculdade, ele não existe, é um ou outro né!? O enfermeiro, ele é um tarefeiro... Parece que ele aliou ao Sistema, aliou a normas e rotinas do hospital e não faz diferente, não faz nada pra mudar (Pérola). Só que, na prática, a gente vê que é completamente diferente, o enfermeiro é um profissional basicamente subordinado aos médicos (Turquesa). Tem instituições que o enfermeiro não tem autonomia nenhuma, ele segue muitas vezes o que o médico pede (Diamante). O enfermeiro tem passado a ideia de um profissional sem autonomia no seu trabalho (Esmeralda)

\section{Contexto profissional: (des)valorização do enfermeiro}

A imagem profissional pode estar associada à autonomia, ao status, à atuação do profissional no processo de trabalho e a seu reconhecimento/valorização: Eu tinha uma visão que o enfermeiro era valorizado, tinha trabalho definido.. A relação interpessoal dentro de um ambiente hospitalar, eu imaginava que era outra coisa. Hoje, na prática, eu vejo que é totalmente diferente, nós somos desualorizados (Cornalina). Acho que o enfermeiro é um profissional pouco valorizado, sabe, é um profissional que tem muitas responsabilidades e pouco reconhecimento (Diamante). O enfermeiro é um cuidador, mas que não é valorizado. Nos estágios, a gente tá vendo isso, a remuneração dele é péssima, eu penso que ele se doa demais e as pessoas veem de menos nele (Citrino). Nós somos desualorizados.. e nós somos desunidos entre classe mesmo. Não somos reconhecidos, e isso me deixa um pouco triste porque eu tinha uma visão antes, e hoje eu tenho uma visão totalmente diferente (Cornalina).

Alguns acadêmicos percebem uma imagem valorizada: Eu entrei na graduação. Parece que uma luz iluminou tudo... A gente vê realmente o papel do enfermeiro e o papel do técnico... O enfermeiro pra mim realmente tá sendo muito valorizado (Ônix).

Considerando o valor social da profissão e a amplitude de competências e habilidades que o profissional enfermeiro tem a desempenhar, os resultados apresentam que a valorização da enfermagem deveria ser um de seus atributos.

\section{DISCUSSÃO}

A experiência prática permite ao estudante construir uma identidade profissional própria. A atuação profissional pode influenciar na transformação de conhecimentos, atitudes e habilidades e faz-se necessário que o cenário de prática seja 
um ambiente que promova empatia, confiança, paciência e respeito para com os estudantes de enfermagem ${ }^{(9)}$.

A imagem do enfermeiro apresentada é a de um profissional necessário e fundamental no cenário da saúde, indispensável na Unidade, identificada pela forma de atuação desse profissional. Ao cuidar, a presunção é de que o enfermeiro possa ver a pessoa além de sua enfermidade, esse é um artifício prático para despertar o senso de habilidade profissional de relacionar o ser em seu ambiente diverso e suas relações culturais ${ }^{(10)}$.

O enfermeiro carece de atualização contínua, não pode se restringir à aprendizagem adquirida na graduação, e deve atuar como multiplicador dos saberes que necessitam ser socializados com a equipe para que ambos possam se aprimorar permanentemente ${ }^{(11)}$.

O discente expõe sua preocupação ao perceber o enfermeiro como um profissional alienado no sistema. Alunos devem se formar críticos e problematizadores sobre a atuação de enfermeiros que realizam ações mecânicas e tarefeiras. "Assim, analisar o trabalho da Enfermagem relacionado aos atributos de profissão requer olhar para a utilidade social deste trabalho, assim como para os determinantes histórico-sociais de seu papel no campo multiprofissional de saúde"(12:40)

A submissão da enfermagem à medicina é causada pela própria história da profissão, na qual se esperava dos enfermeiros uma postura caridosa, que fossem capazes de cumprir tarefas prescritas pelos médicos e que cuidassem dos aspectos administrativos do serviço. Com o passar do tempo, essa função se modifica passando o enfermeiro a ser auxiliar do médico, uma estreita relação entre o modelo religioso e a submissão à autoridade médica. Toda essa dependência do conhecimento médico, associada à submissão imposta pelos médicos, é um dos fatores que ainda influencia na postura do corpo da enfermagem ${ }^{(13)}$. Para compreendermos o nosso presente, fazemos comparações com os momentos do passado(7), o que vem ocorrendo com a imagem do enfermeiro.

A atuação, o perfil do profissional enfermeiro e a autonomia, bem como a comunicação efetiva com o acadêmico, têm implicações na construção da imagem do enfermeiro perante o estudante de graduação. A imagem do enfermeiro concebe um conjunto de representações sociais, as quais por meio de conceitos, afirmações, explicações, reproduzem e são reproduzidas pelas ideologias geradas no dia a dia das práticas sociais, interno-externa a ela. Para Maffesoli(7), o conjunto de representações e suas combinações constituem motores sociais por excelência. Por isso, a projeção de uma imagem negativa dificulta o desenvolvimento da profissão, influencia em sua prática e diminui seu reconhecimento social.

Provocar mudanças na imagem da profissão, provavelmente, exija a veiculação, de forma verossímil, da Enfermagem, instrumentalizando os profissionais da comunicação acerca do conhecimento sobre essa profissão, punindo a comunicação de inverdades divulgadas ${ }^{(14)}$.

O acadêmico assimila cuidado com valorização do enfermeiro. O cuidado significa zelo, atenção, solicitude e se concretiza no contexto da vida em sociedade. Assim, compreender o valor do cuidado de enfermagem exige uma compreensão ética que contemple a vida como sendo um bem valioso em si. começando pela valorização da própria vida ${ }^{(15)}$

A imagem de valorização do enfermeiro pode ser influenciada negativamente pela desunião. Vários fatores interferem na relação interpessoal da equipe de enfermagem: descompromisso com os objetivos do trabalho; personalidade dos membros do grupo; disputa de poder entre os integrantes; problemas pessoais e com familiares interferindo no desempenho profissional; nivel de escolaridade diversificado e o egoísmo. Ademais, a desmotivação pelos baixos salários, relações conflituosas em diferentes níveis hierárquicos, problemas no desempenho de funções pela falta de conhecimentos, habilidades e inaptidão dificultam também esse relacionamento entre enfermeiros ${ }^{(16)}$.

Como limitação para os avanços na autonomia e na valorização do enfermeiro apontam-se a fragilidade política dos seus discursos; a pouca apropriação sobre a historicidade da profissão; o apego a imagens idealizadas da enfermagem, que não correspondem à realidade da prática social; a precarização das relações e das condições de trabalho nos serviços. Há de se desenvolver uma cultura crítica de reflexão sobre as fragilidades políticas da enfermagem, para que a busca pela autonomia seja um exercício da qualidade 
do seu fazer ${ }^{(17)}$.

Os relatos explicitam que o acadêmico se espelhará na imagem positiva do enfermeiro competente, habilidoso, ético e compromissado. Destarte, é imperiosa a necessidade de o enfermeiro atentar para sua atuação no ambiente de trabalho, nas relações interpessoais, no enfrentamento de conflitos, enfim, na prática diária tanto assistencial quanto gerencial.

Considerando o valor social da profissão e a amplitude de competências e habilidades que o profissional enfermeiro tem a desempenhar, os resultados apresentam que a valorização da enfermagem deveria ser um de seus atributos.

\section{CONCLUSÃO}

Os resultados apresentam que a imagem do enfermeiro frente ao acadêmico se postula em um profissional essencial na área da saúde, que organiza o setor, gerencia ações, lidera a equipe, presta assistência aos pacientes e é referência para outros profissionais. Porém, a insatisfação do acadêmico é presente ao receber um tratamento indiferente dos enfermeiros dos setores onde vivenciaram a prática em estágios.

Os quesitos que qualificam o enfermeiro são fonte de referência para aqueles que pretendem seguir essa profissão. A relação profissional-acadêmico com comunicação efetiva é essencial para a formação de um profissional preparado para a atuação em equipe multiprofissional e em ações interdisciplinares.

A (des)valorização do profissional foi um dos aspectos na construção dessa imagem e na percepção positiva/negativa do acadêmico frente ao futuro na profissão.

Com os resultados do presente estudo com discentes, sugere-se o conhecimento da imagem do enfermeiro frente aos docentes, gestores do ensino e dos próprios enfermeiros que supervisionam estágios curriculares da graduação em enfermagem.

\section{REFERÊNCIAS}

1. Vale EG, Pagliuca LMF. Construção de um conceito de cuidado de enfermagem: contribuição para o ensino de graduação. Rev. bras. enferm. 2011; 64(1): 106-113.

2. Campos PFS, Oguisso T. A Escola de Enfermagem da Universidade de São Paulo e a reconfiguração da identidade profissional da Enfermagem Brasileira. Rev. bras. enferm., 2008; 6l(6):892-898.

3. Machado MH, Filho WA, Lacerda WF, Oliveira E, Lemos W, Wermelinger $M$, et al. Caracteristicas gerais da enfermagem: o perfil sócio demográfico. Enferm. Foco 2015; 6 (1/4): 11-17.

4. American Psychological Association. Dicionário de Psicologia APA. Artmed, 1 ed, 2010. p. 1042

5. Fonseca LF, Silva MJP. Desafiando a imagem milenar da enfermagem perante adolescentes pela internet: impacto sobre suas representações sociais. Cienc Cuid Saude 2012; 11(suplem.):054-062.

6. Yin RK. Estudo de caso: planejamento e métodos. Tradução de Crsithian Matheus Herrera. 5. ed. Porto Alegre: Bookman, 2015. 290 p.

7. Maffesoli M. O conhecimento comum: introdução à sociologia compreeensiva. Traduzido por Aluizo Ramos Trinta. Porto Alegre: Sulina 2010. 295 p.

8. Bardin L. Análise de conteúdo. Tradução de Luís Antero Reto, Augusto Pinheiro. São Paulo: Edições 70, 2011. 279 p.

9. Merighi MAB, Jesus MCP, Domingos SRF, Oliveira DMO, Ito TN. Ensinar e aprender no campo clinico: perspectiva de docentes, enfermeiras e estudantes de enfermagem. Rev Bras Enferm. 2014;67(4):505-11

10. Viegas SMF, Penna CMM. A construção da integralidade no trabalho cotidiano da equipe saúde da família. Esc. Anna Nery. 2013; 17(1): 133-141

11. Amestoy SC, Backes VMS, Trindade LL, Canever BP. Produção científica sobre liderança no contexto da enfermagem. Rev. esc. enferm. USP, 2012 46(1): 227-33

12. Pires DP. Transformações necessárias para o avanço da Enfermagem como ciência do cuidar. Rev. bras. enferm. 2013 ; 66(spe): 39-44

13. Ribeiro JMS. Autonomia profissional dos enfermeiros. Rev. Enf. Ref. Coimbra, 2011; serIII(5): 27-36

14. Avila LI, Silveira RS, Silveira JT, Lunardi VL, Ommeren LV, Fernandes GFM. Visibilidade da enfermagem sob a ótica de universitários. Enferm. Foco 2013; 4(3,4) 211 - 214

15. Déborah Ramos KRR, Mesquita SKC, Galvão MCB, Enders BC. Paradigmas da saúde e a (des)valorização do cuidado em enfermagem. Enfermagem em Foco 2013; 4(1): 41-44

16. Corradi EM, Zgoda LTRW, Paul MFB. O gerenciamento de conflitos entre a equipe de enfermagem. Cogitare Enferm., 2008; 13(2): 184-193

17. Pires MRGM. Limites e possibilidades do trabalho do enfermeiro na estratégia saúde da familia: em busca da autonomia. Rev. esc. enferm. USP. 2011; 45( spe2): 1710-1715 